\begin{tabular}{|l|l|}
\hline Postprint Version & 1.0 \\
\hline Journal website & $\begin{array}{l}\text { http://www.informaworld.com/smpp/content } \sim \mathrm{db}=\text { all } \sim \text { content=a927210937 frm } \\
=\text { abslink }\end{array}$ \\
\hline Pubmed link & $10.1080 / 07481181003765444$ \\
\hline DOI & \\
\hline
\end{tabular}

This is a NIVEL certified Post Print, more info at http://www.nivel.eu

\title{
IMAGINING THE IMPACT OF DIFFERENT CONSENT SYSTEMS ON ORGAN DONATION: THE DECISIONS OF NEXT OF KIN
}

\author{
REMCO COPPEN $^{1}$; ROLAND D. FRIELE ${ }^{1,2 ;}$ SJEF K. M. GEVERS ${ }^{3}$, JOUKE VAN DER ZEE ${ }^{1,2}$
}

${ }^{1}$ NIVEL (Netherlands Institute for Health Services Research), Utrecht, The Netherlands

${ }^{2}$ Utrecht, and Tranzo (Scientific Centre for Transformation in Care and Welfare), Tilburg University, Tilburg, The Netherlands

${ }^{3}$ Department of Social Medicine (Health Law Section), Academic Medical Center, University of Amsterdam, Amsterdam, The Netherlands

${ }^{4}$ Utrecht, and Faculty of Health, Medicine, and Life Sciences, Department of International Health, Maastricht University, Maastricht, The Netherlands

Next of kin play an important role in organ donation. The aim of this study was to assess the extent to which explicitness of consent to organ donation by the deceased impacts the likelihood that next of kin will agree to organ donation of the deceased by using hypothetical cases. Results indicate that that people say they are more willing to agree to donate organs of those who explicitly consented to donate than those whose permission to donate is presumed. The degree of explicitness for the consent to donate by the deceased appears to influence the next of kin's decision about whether to agree to donation. This variation might explain the absence of differences in efficiency between various types of consent systems.

The need for organs suitable for transplantation is acute. For example, in The Netherlands in 2006, there were 1,441 people on a waiting list for transplantation. However in that same year, donations by only 200 postmortem organ donors were procured (Dutch Transplantation Foundation, 2007). Other countries experience the same problem (Council of Europe, 2008). The shortage of procured postmortem organs is forcing countries to develop policies to optimize efficiency in retrieving postmortem organs from potential donors. An important issue in the donation process that causes a loss of donors is obtaining consent for an organ donation procedure (Frutos et al., 2005; Klenow \& Youngs, 1995; Siminoff, Arnold, Caplan, Virgnig, \& Seltzer, 1995; Stein, Hope, \& Baum, 1995). There is general agreement that the procurement of organs postmortem is only allowed if the deceased or his or her next of kin consented to organ donation. In general, there are two legal systems for obtaining consent: explicit consent and presumed consent (Gevers, Janssen, \& Friele, 2004). In an explicit consent system the donor himself or herself has to authorize organ removal after his or her death in the form of an advance directive or donor codicil, or by filling in a form to record consent in a national registry. If the deceased's wish is not known, the next of kin are consulted. On the other hand, under a strict presumed consent system, it is not required to obtain consent-either from the deceased or from the next of kin; it is sufficient to verify that the deceased did not object during his or her lifetime to becoming a donor (Gevers et al., 2004). Irrespective of the consent system, most people do not register their wishes (whether consent or refusal; Gä bel, 2003, 2006). The consequence of this is that the pool of consenting donors in a presumed consent system far exceeds the pool of consenting donors in an 
explicit consent system (Johnson \& Goldstein, 2003). This would suggest a more efficient procurement (i.e., larger numbers) of organ donors in presumed consent countries. However, several studies show that there is no substantial difference in the efficiency of procurement between both consent systems (Cameron \& Forsythe, 2001; Matesanz, 1998). When differences in the organ donation rates between countries are adjusted for differences in the numbers of potential donors based on relevant mortality rates, presumed consent systems do not guarantee higher efficiency of donor procurement (Coppen, Friele, Gevers, Blok, \& Zee, 2008; Coppen, Friele, Marquet, \& Gevers, 2005). A possible explanation for this surprising finding may lie in the role of next of kin. Gevers et al. (2004) concluded that in Western European countries, regardless of the legal consent system, next of kin play an important role in obtaining consent. In an explicit consent system, next of kin are consulted when the deceased's wishes are unregistered; further, even when the deceased is an explicit donor, next of kin play a role in the procurement process (Friele et al., 2004). In addition, in presumed consent systems, too, next of kin are given a voice when the wishes of the deceased are unknown - even though consent is presumed (Childress \& Liverman, 2006; Chouhan \& Draper, 2003; Galea \& Pegg, 2003; Gevers et al., 2004; Janssen \& Gevers, 2005; Matesanz, 1998; Prottas, 1985). Therefore, in Western European countries next of kin are always consulted during the organ procurement process, regardless of the legal conditions of the donor (i.e., explicit donor, presumed donor, or nonregistered). Next of kin are not consulted only when the deceased made an objection against donation because the deceased will not be a donor in that case. Because next of kin play a role in whether organs are donated, a large donor pool filled with presumed consents will result in a much smaller pool of donors if next of kin withhold their approval. On the other hand, countries with a small donor pool filled with explicit consents may suffer far less from this phenomenon if next of kin follow the explicit wishes of the deceased. Because of a lack of impact of the current donor legislation, a number of interest groups (e.g., several political parties, patient organizations, and the Netherlands Institute for Health Promotion and Disease Prevention) joined together and looked for ways to ameliorate the performance of the Dutch Organ Donation Act. In order to create a large donor pool filled with registered consents, they have proposed to combine what they see as the best of both systems: a system with automatic consent registration in the national donor registry. To obtain an automatic consent registration, these interest groups have proposed that all citizens not yet registered in the national registry should be sent a letter to inform them that if they do not explicitly refuse to be a donor they will automatically be registered as a donor in the national registry. To verify whether a person really wants to be registered, the individual will receive a follow-up letter which confirms his or her registration (Friele \& Jong, 2007; Friele \& Kerssens, 2004). Because of the role that next of kin play, it is important for professionals and policy makers to know whether the different legal conditions of donors influence next of kin in their decision to agree to an organ donation procedure and to get insight into how this mechanism works. Hence, the aim of this study was to assess the extent to which explicitness of consent to organ donation by the deceased impacts on the likelihood that next of kin will agree to the procurement of the deceased's organs. It is assumed that next of kin of explicit donors are more willing to agree than next of kin of presumed donors so we tested this assumption.

\section{METHOD}

\section{Sample}

This study was conducted via the Dutch Health Care Consumer Panel (DHCP), a panel on consumers' experiences and opinions regarding health services. The DHCP is representative of the general Dutch population in terms of age and gender. To ensure that the panel continues to represent a cross-section of the population, every 2 years one-third of the consumer panel is renewed. This also prevents panel members from developing specific knowledge or awareness of certain health care issues or "questionnairefatigue" (Schee, Groenewegen, \& Friele, 2006).

\section{MATERials}

The questionnaire consisted of four hypothetical cases that were presented to all respondents. Each hypothetical case described a situation in which a close family member had been declared brain dead by a physician. The cases varied with respect to the degree with which consent was made explicit:

Case 1: The deceased is registered as a donor in an explicit consent system. 
Case 2: The deceased is not registered as a donor in an explicit consent system.

Case 3: The deceased is presumed to be a donor in a presumed consent system.

Case 4: The deceased is automatically registered as a donor in an alternative system proposed in The Netherlands. Cases 1 and 2 occur in explicit consent systems. Case 3 occurs in presumed consent systems. Case 4 is derived from the system with automatic consent registration proposed by a number of interest groups in The Netherlands. For each case two questions were asked: (a) "Taking into account the cited (legal) conditions, would you as next of kin of the deceased agree to an organ donation procedure?'; and (b) "Taking into account the cited legal conditions, would you approve a situation in which you are not consulted at all?'” The respondents only had the option of answering both questions with "Yes," "'No," or

"I don't know." The respondents were not given the opportunity to explain their answers.

\section{Data Analysis}

The questionnaire was first sent to 669 members of the DHCP in 2004 (response rate 98\%). To confirm the sustainability of the results, we repeated the study in a renewed DHCP in 2007. The response rate in 2007 was $80 \%$ (1,376 questionnaires were sent out and 1,094 were returned). The number of questionnaires sent out in 2004 was much smaller than in 2007 because the DHCP was smaller at that time. Because the gender, consent registration, and age distribution of the respondents differed slightly from the Dutch population, we controlled the data for these factors in both years. For both years a weight factor (\% of the Dutch population/\% respondents) was used to make the DHCP comparable with the Dutch population. A total of 20 weight factors were used for the combination of gender (male, female), consent registration (registered with consent, not registered), and age (0-34, 35-44, 45-54, 55-64, and 65 and older).

\section{RESULTS}

First, this section gives insight into the reported willingness of next of kin to donate within different hypothetical legal scenarios. Our results reveal similarities and/or differences between the different legal scenarios. Second, this section gives insight into their preferred position within these different systems for organ donation and addresses whether the respondents will approve a situation in which next of kin are not consulted at all. We report 95\% confidence intervals (CIs) and used them to determine significant differences between cases. When the $95 \%$ CIs of the results do not overlap each other, there is a statistically difference between these cases.

\section{Willingness to Donate Within Different Legal Scenarios}

Figure 1 shows that respondents, in their role as next of kin, say they are most often willing to agree to donate the organs of a deceased relative when he or she is registered as a donor and an explicit consent system is in place (Case 1: 73\%; 95\% CI 70.3-75.6). Where registration is absent, the respondents say they are more likely to agree to donate when a presumed consent system (Case 3: 48\%; 95\% CI 45.3-51.3) is in force than when an explicit consent system is in force (Case 2: 30\%; 95\% CI 27.7-33.1). The results also indicate that the respondents make a distinction between presumed donors (Case 3 ) and automatically registered potential donors (Case 4: 61\%; 95\% CI 58.5-64.4). Figure 1 also shows that the respondents are more likely to refuse to donate the organs of a deceased relative when there is no registration (Cases 2 and 3). The absence of registration in an explicit consent system (Case 2: 41\%; 95\% CI 37.7-43.6) leads to a significantly higher refusal rate than the absence of registration in a presumed consent system (Case 3 : 34\%; 95\% CI 31.6-37.2).

\section{[FIGURE 1]}

\section{Preferred Position of Next of Kin Across Types of Procurement Systems}

Figure 2 shows that, regardless of the type of system, respondents want to have a say in whether the organs of a deceased relative are donated. On average, two-thirds of the respondents would not approve a situation in which next of kin are not consulted at all. The figure shows that respondents, in their role as next of kin, feel a greater need to be consulted when there is no consent or when consent is presumed than when consent is explicit. 


\section{[FIGURE 2]}

\section{DISCUSSION}

The aim of our study was to assess the extent to which explicitness of consent to organ donation by the deceased impacts on the likelihood that next of kin will agree to the procurement of the deceased's organs. This section reviews the findings that (a) explicit consent is more likely to result in agreement to organ donation and (b) most next of kin want to be involved in the decision about organ donation and discusses the study's limitations.

\section{Explicit Consent Is Most Likely to Result in Agreement to Organ Donation}

There are considerable differences in how people say that they think they will react as next of kin to the question of whether to agree with the procurement of the organs of a close family member. They report that their reaction will depend on the applicable legal conditions. According to our results, the likelihood that next of kin will agree to organ donation increases when the consent of the deceased is explicit. When the deceased is an explicit donor, the next of kin report being more likely to actually donate an organ than when consent is presumed. Thus, we conclude that in a presumed consent system, the pool of consenting donors is large, but the likelihood that next of kin will agree with donation is lower; however, in an explicit consent system the pool of consenting donors is small, but the likelihood that next of kin will agree is larger. This might explain the absence of a clear difference in the efficiency of donor procurement between presumed consent countries and explicit consent countries. It is noteworthy that an explicit consent system can only accomplish the above effect when a significant part of the population is registered or carries a donor card. For example, in The Netherlands, approximately $40 \%$ of the population is registered in the Donor Register. This register contains three types of registration: registered consent (57\%), registered refusal (30\%), and registered next of kin (or a specified person) may decide upon the organ donation (13\%; Dutch Transplantation Foundation, 2008). To our knowledge no other country has a register with such high registration rates (Gä bel, 2003). These results parallel previous findings. New results in this study are that the respondents, in their role as next of kin, distinguish between explicit donors, presumed donors, automatic donors, and nonregistered persons when agreeing to the procurement of organs of a deceased person. In hospital-based studies that analyzed differences between next of kin who agreed with the procurement of organs of a deceased person and next of kin who refused, it was also found that when the next of kin were convinced that it was the deceased's wish to donate his or her organs, they were more likely to agree (Farsides, 2000; Flode' n, Kelvered, Frid, \& Backman, 2006; Frutos et al., 2005; Martı́nez et al., 2001; Rosel, Frutos, Blanca, \& Ruiz, 1999; Siminoff et al., 1995; Siminoff, Arnold, \& Hewlett, 2001; Siminoff, Gordon, Hewlett, \& Arnold, 2001; Sque, Long, \& Payne, 2005). Furthermore, the analysis of organ donation procedures in 57 Dutch hospitals supports these findings. In that study 1,131 deceased persons were identified as potential donors. When consent of the donors was registered, $92 \%$ of the next of kin agreed with an organ donation procedure (Friele et al., 2004).

\section{Most Next of Kin Want to Be Involved in the Decision About Organ Donation}

Another relevant observation in this study is that about two-thirds of the Dutch respondents report that they would not approve a consent system in which they (as next of kin) are not consulted. The study also indicates that the more the respondents are convinced that organ donation is exactly what the potential donor wanted, the less importance they attach to being involved in the decision-making process. It seems that the respondents experience more confidence in donating organs when consent is made more explicit. Most respondents reported that next of kin should have a say in whether a donation procedure is performed, regardless of the presence of explicit, presumed, or automatic registration. Siminoff and Mercer (2001) reported a similar finding and argued that people are distrustful of strangers making decisions about a deceased's body. They noted that people "are clearly more comfortable to know that family members have a final say”' (Siminoff \& Mercer, 2001, p. 385). These results show that people, in their imagined role as next of kin, also want to take up this role and have a final say.

\section{Limitations of This Study}

The main limitation of this survey is that it sheds light on what people believe they would do in hypothetical circumstances. When people are actually confronted with the question of donating the organs of a deceased relative, they tend to be more cautious (Dyer, 2007; Klassen \& Klassen, 1996; Siminoff et al., 1995). In the case of organ donation, a cautious decision is a refusal. Secondly, people were asked to 
provide their answers in only three categories: "Yes," “No,” or "'I don’t know.” In reality, when consulting next of kin, questions may be asked, uncertainties addressed, and feelings exchanged (Simpkin, Robertson, Barber, \& Young, 2009). All of these factors will contribute to the final decision. The impact of this process cannot be accounted for in this study. Another limitation of this study is that it only sheds light on the Dutch situation (our current system is an explicit consent system). Because there are no valid, reliable data on refusal rates at an international level, it is difficult to study next of kin decisions between countries with different consent systems. It would be relevant to test whether our results can also be replicated in other countries. For now, it is important to see that, according to our results, families distinguish between presumed and explicit donors.

\section{CONCLUSION}

This research shows that the degree to which consent is made explicit by the legislative consent system seems to affect the willingness of the Dutch population in its role as next of kin to agree with an organ donation procedure. Respondents said they are more likely to agree with the procurement of the organs of an explicit donor than of a presumed donor. Taking into account that it is more likely that the organs of an explicit donor are procured than those of a presumed donor, this might explain the absence of clear differences in the efficiency of donor procurement between presumed and explicit consent systems. Moreover, respondents made it clear that they would not approve a consent system in which they are not consulted. Apparently, the belief that they have the possibility to agree or disagree with an organ donation procedure is comforting and contributes to their sense of justice. Moreover, having the possibility to agree or disagree with an organ donation seems to support next of kin in their responsibility for taking care of the deceased's body. This may explain why in most countries, regardless of consent system, next of kin play an important role (Chouhan \& Draper, 2003) and is in line with the finding of Gevers et al. (2004) " that in reality the different systems are much more similar than suggested by the explicit/presumed consent distinction”' (p. 184; see also Childress \& Liverman, 2006; Galea \& Pegg, 2003; Janssen \& Gevers, 2005; Matesanz, 1998; Prottas, 1985). Thus, next of kin do matter when a decision regarding organ donation is made. This study shows that is it important that people inform their relatives about the wish to become an organ donor and to confirm that wish either by registering in a national register or by document (e.g., donor card, driver's license; Alleman, Coolican, Savaria, Swanson, \& Townsend, 1996; Childress \& Liverman, 2006; Farsides, 2000; Simpkin et al., 2009). When searching for nonlegal strategies to increase the consent rate regarding organ donation, governments or organ procurement organizations could implement this suggestion into a communication package aimed at the general population: Let your next of kin know that you want to be a donor and confirm that wish.

\section{REFERENCES}

Alleman, K., Coolican, M., Savaria, D., Swanson, M., \& Townsend, M. (1996). Public perceptions of an appropriate donor card/brochure. Journal of Transplant Coordination, 6, 105-108.

Cameron, S., \& Forsythe, J. (2001). How can we improve organ donation rates? Research into the identification of factors which may influence the variation. Nefrologia, 11, 68-77.

Childress, J. F., \& Liverman, C. T. (Eds.). (2006). Organ donation: Opportunities for action. Washington, DC: National Academy of Sciences.

Chouhan, P., \& Draper, H. (2003). Modified mandated choice for organ procurement. Journal of Medical Ethics, 29, 157-162.

Coppen, R., Friele, R. D., Gevers, J. K. M., Blok, G. A., \& Zee, J. v. d. (2008). The impact of donor policies in Europe: A steady increase, but not everywhere. BMC Health Services Research, 8, 235-244.

Coppen, R., Friele, R. D., Marquet, R. L., \& Gevers, J. K. M. (2005). Opting-out systems: No guarantee for higher donation rates. Transplant International, 18, 1275-1279.

Council of Europe. (2008). International figures on organ donation and transplantation: Year 2007.

Transplant Newsletter, 13, 3-22.

Dutch Transplantation Foundation. (2007). Annual report 2006. Leiden, The Netherlands: Author.

Dutch Transplantation Foundation. (2008). Annual report 2007. Leiden, The Netherlands: Author.

Dyer, C. (2007). Two thirds favour organ donation after death, but only one in 20 take steps to facilitate it.

British Medical Journal, 335, 533. 
Farsides, T. (2000). Winning hearts and minds: Using psychology to promote voluntary organ donation. Health Care Analysis, 8, 101-121.

Flode' n, A., Kelvered, M., Frid, I., \& Backman, L. (2006). Causes why organ donation was not carried out despite the deceased being positive to donation. Transplantation Proceedings, 38, 2619-2621.

Friele, R. D., Gevers, J. K. M., Coppen, R., Janssen, A. J. G. M., Brouwer, W., \& Marquet, R. L. (2004). Second evaluation of the Organ Donation Act. The Hague, The Netherlands: ZonMW.

Friele, R. D., \& Jong, J. D. (2007). Actieve Donorregistratie? [Active donor registration? ] Utrecht, The Netherlands: NIVEL.

Friele, R. D., \& Kerssens, J. J. (2004). Actieve Donorregistratie? Een onder zoek naar de mogelijke reacties op de introductie van een actieve donorregistratie [Active donor registration? A study on the possible reactions to the introduction of an alternative system of donor registration]. Utrecht, The Netherlands: NIVEL.

Frutos, M. A., Blanca, M. J., Mansilla, J. J., Rando, B., Ruiz, P., Guerrero, F., et al. (2005). Organ donation: A comparison of donating and nondonating families. Transplantation Proceedings, 37, 1557-1559.

Gä bel, H. (2003). Donor registries throughout Europe and their influence on organ donation.

Transplantation Proceedings, 35, 997-998.

Gä bel, H. (2006). Organ donor registers. Current Opinion in Organ Transplantation, 11, 187-193.

Galea, G., \& Pegg, D. (2003). The ethics of donation: Changes are necessary and soon. The Lancet, 362, 932.

Gevers, J., Janssen, A., \& Friele, R. (2004). Consent systems for post mortem organ donation in Europe. European Journal of Health Law, 11, 175-186.

Janssen, A., \& Gevers, J. (2005). Explicit or presumed consent and organ donation post-mortem: Does it matter? Medicine and Law, 24, 575-583.

Johnson, E. J., \& Goldstein, D. (2003). Medicine: Do defaults save lives? Science, 302, 1338-1339.

Klassen, A. C., \& Klassen, D. K. (1996). Who are the donors in organ donation? The family's perspective in mandated choice. Annals of Internal Medicine, 125, 70-73.

Klenow, D. J., \& Youngs, G. A., Jr. (1995). An empirical exploration of selected policy options in organ donation. Death Studies, 19, 543-557.

Martínez, J. M., Lo' pez, J. S., Martín, A., Martín, M. J., Scandroglio, B., \& Martín, J. M. (2001). Organ donation and family decision-making within the Spanish donation system. Social Science \& Medicine, 53 , 405-421.

Matesanz, R. (1998). Cadaveric organ donation: Comparison of legislation in various countries of Europe. Nephrology, Dialysis, Transplantation, 13, 1632-1635.

Prottas, J. M. (1985). Organ procurement in Europe and the United States. Milbank Memorial Fund Quarterly/Health and Society, 63, 94-126.

Rosel, J., Frutos, M. A., Blanca, M. J., \& Ruiz, P. (1999). Discriminant variables between organ donors and nondonors: A post hoc investigation. Journal of Transplant Coordination, 9, 50-53.

Schee, E. v. d., Groenewegen, P. P. v., \& Friele, R. D. (2006). Public trust in health care: A performance indicator? Journal of Health Organization and Management, 20, 468-476.

Siminoff, L. A., Arnold, R. M., Caplan, A. L., Virgnig, B. A., \& Seltzer, D. L. (1995). Public policy governing organ and tissue procurement in the United States: Results from the National Organ and Tissue Procurement Study. Annals of Internal Medicine, 123, 10-17.

Siminoff, L. A., Arnold, R. M., \& Hewlett, J. (2001). The process of organ donation and its effect on consent. Clinical Transplantation, 15, 39-47.

Siminoff, L. A., Gordon, N., Hewlett, J., \& Arnold, R. M. (2001). Factors influencing families' consent for donation of solid organs for transplantation. Journal of the American Medical Association, 286, 71-77. Siminoff, L. A., \& Mercer, M. B. (2001). Public policy, public opinion, and consent for organ donation. Cambridge Quarterly of Healthcare Ethics, 10, 377-386.

Simpkin, A. L., Robertson, L. C., Barber, V. S., \& Young, Y. D. (2009). Modifiable factors influencing relatives' decision to offer organ donation: Systematic review. British Medical Journal, 338, 991.

Sque, M., Long, T., \& Payne, S. (2005). Organ donation: Key factors influencing families' decision-making. Transplantation Proceedings, 37, 543-546.

Stein, A., Hope, T., \& Baum, J. D. (1995). Organ transplantation: Approaching the donor's family. British Medical Journal, 310, 1149-1150. 
Coppen, R., Friele, R.D., Gevers, J.K.M., Zee, J. van der. Imagining the impact of different consent systems on organ donation: the decisions of next of kin. Death Studies: 2010, 34(9), 835-847

\section{[TABLES AND FIGURES]}

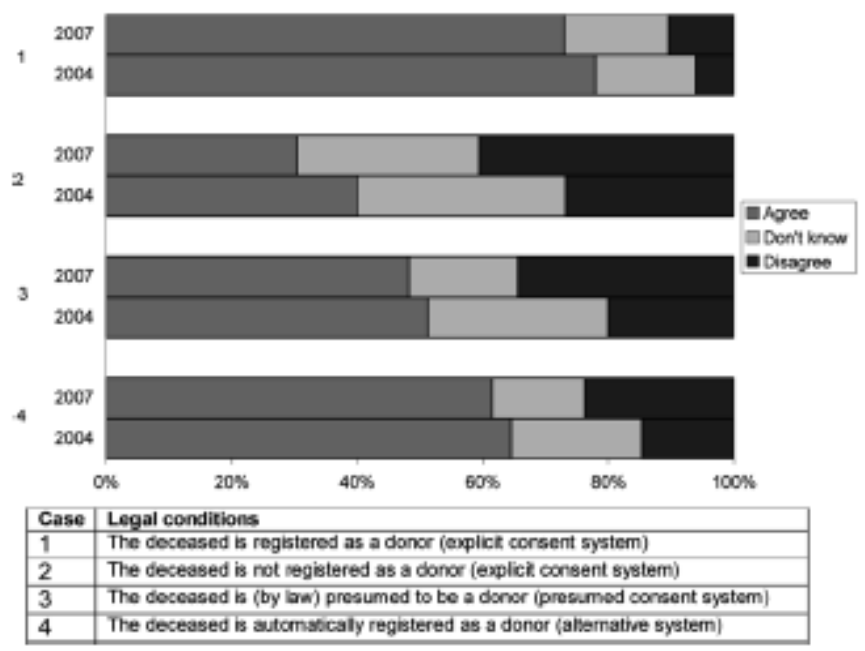

FIGURE 1 Four hypothetical cases and the decisions the sample would make if they (as next of kin) were asked to consent to the organ donation procedure of a potential donor.

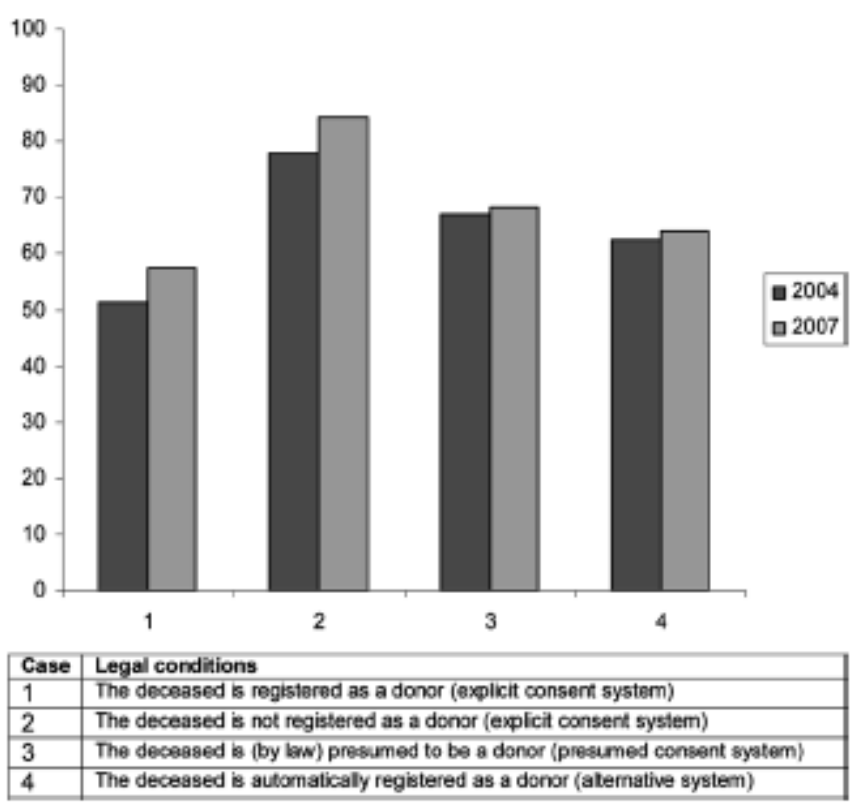

FIGURE 2 Percentage of next of kin in the sample who would not approve a situation in which they are not consulted. 